\title{
Analysis of association of two SNP in cholecystokinin $B$ receptor gene with behaviour scores in German Angus and German Simmental cattle (Brief Report)
}

\author{
Assoziationsanalyse zweier SNP im Cholecystokininrezeptor B Gen mit \\ Verhaltensmerkmalen bei Deutsche Angus und Deutsches Fleckvieh (Brief Report)
}

KRISTINA GLENSKE' ${ }^{1}$ HORST BRANDT ${ }^{1}$, MATTHIAS GAULY² and GEORG ERHARDT ${ }^{1}$

'Department of Animal Breeding and Genetics, Justus-Liebig-University of Giessen, Giessen, Germany, ${ }^{2}$ Department of Animal Science, Georg-August-University of Göttingen, Göttingen, Germany

\section{Background}

Behaviour including temperament of cattle especially suckler cows is important for the safety of stockmen and animals. The temperament of cattle can be defined as the answer to human handling situations (BURROW 1997) and can be measured for calves in different tests like tethering test, weighing test or separation- and restraint test (TULLOH 1961, BOISSY and BOUISSOU 1988, LE NEINDRE et al. 1995). The heritabilities for behaviour-traits ranged from 0.02 to 0.33 (GAULY et al. 2002). In this study the cholecystokinin B receptor gene is analysed. This candidate gene is important in the regulation of anxiety in rats (WANG et al. 2005) and in humans (HÖSING et al. 2004). In different tests with CCKBR-knockout mice they show more exploratory activity than the wild type mice (RAUD et al. 2003) and less anxious behaviour (HORINOUCHI et al. 2004).

\section{Procedures}

\section{Phenotypes}

German Angus (GA) and German Simmental (GS) calves were evaluated in three behaviour tests as mentioned within background. In total 962 calves of six GA-sires (545 calves) and eight GS-sires (417 calves) born in four consecutive years were included. Four scores were distributed in the three behaviour tests: one for tethering test (TT, three weeks of age), one for separation- and restraint test (ST, seven to eight month of age) and two for the weighing test at three month of age. The first score for weighing test was given while entering the scale (WT1) and the second during weighing process (WT2). All scores ranged from 1=docile, calm to $5=$ very excited and were nearly normally distributed with a left tendency.

\section{Detection of single nucleotide polymorphisms}

Two PCR-fragments of bovine CCKBR (GenBank NW_001493314) were sequenced; one fragment including the region from exon III to exon IV (688 bp, primer f1: 5'-GGG TGT CTG TGA GCG TGT C-3', r1: 5'-GCA GCC CTC CCT GAC TTC-3') and the other one covered the $3^{\prime} U T R$ (790 bp; primer f2: 5'-TCA CTG TCC AGG CTG AGC TA-3', r2: 5'-GCG TAT TCC ACC CCT AAC CT-3'). 
In both fragments synonymous C/T-SNPs were identified and used to establish different methods for genotyping. The SNP in intron 3 was genotyped by PCR-RFLP-analysis with BseNI (primer in3f: 5'-ACC CAG AAT CTT GCT CCA AC-3', in3r: 5'-AGT CAG TGC GGA TCC CTG T-3') and the one in $3^{\prime} U T R$ with tetra-primer ARMS-PCR-analysis (primer outF: 5'-GTA TAG CAG GGG CAT TGA ATC TTT CAG G-3', outR: 5'-AAA AAG GAA ATT GAG GGG GAA ACC AAG T-3', inF: 5'-CAC CAA CCT GCC TAA TCT CAC ACT CAC T-3', inR: 5'-TCT TAG TGC AAA ACA GCT CGT TGG TAC G-3').

\section{Statistical analyses}

Association analyses between genotypes at the SNPs and behaviour scores were done within breeds using a variance analysis including sex and genotype as fixed effects, age at test as covariate and sire and residual as random effects. Furthermore the allele frequencies for the SNPs between animals with extreme scores (1 versus 4+5) were compared using the chi ${ }^{2}$-test procedures.

\section{Results and discussion}

Compared to GenBank NW_001493314 the SNP in intron 3 is at position 311275 and the other one in the 3'UTR at position 309831. In the case of allele $C$ in intron 3 the binding site for transcription factor MZF1 (myeloid zinc finger 1) is completed. The genotype- and allelefrequencies for these SNP in the calves are shown in table 1. Noticeable are the missing of genotype $T T$ in intron 3 and $3^{\prime} U T R$ in GS and GA, respectively. The missing TT genotype in GS for intron 3 is expected because all GS sires are homozygous CC. The missing TT genotype in GA for 3'UTR can be explained by the low frequency of the T-allele in GA. Only one of the six GA-sires is heterozygous, while the others are homozygous CC. Only the SNP in intron 3 in GA is not in Hardy-Weinberg-equilibrium.

Table 1

Genotype- and allele-frequencies of both SNPs in CCKBR separated by German Angus (GA) and German Simmental (GS)

Genotyp- und Allelfrequenzen der beiden SNPs im CCKBR getrennt nach den untersuchten Rassen Deutsche Angus (GA) und Deutsches Fleckvieh (GS)

\begin{tabular}{|c|c|c|c|c|c|c|c|}
\hline \multirow{2}{*}{$\begin{array}{l}\text { SNP positions in } \\
\text { NW_001493314 }\end{array}$} & \multirow[t]{2}{*}{ Breed } & \multirow{2}{*}{$\begin{array}{c}\mathrm{N} \text { of } \\
\text { tested animals }\end{array}$} & \multicolumn{3}{|c|}{ Genotype-frequency } & \multicolumn{2}{|c|}{ Allele-frequency } \\
\hline & & & $C C$ & $C T$ & $T T$ & C & $T$ \\
\hline \multirow[t]{2}{*}{ pos. 311275 (intron 3) } & $\mathrm{GA}$ & 542 & 0.55 & 0.35 & 0.10 & 0.73 & 0.27 \\
\hline & GS & 412 & 0.95 & 0.05 & 0.00 & 0.97 & 0.03 \\
\hline \multirow[t]{2}{*}{ pos. 309831 (3'UTR) } & GA & 543 & 0.88 & 0.12 & 0.00 & 0.93 & 0.07 \\
\hline & GS & 417 & 0.60 & 0.35 & 0.05 & 0.78 & 0.22 \\
\hline
\end{tabular}

With the chi'-test procedure only an influence by the intron 3 SNP on score WT2 in GA could be detected with a $P$-value of 0.0431 . In addition a higher frequency of allele $C$ in score 5 than in score 1 was seen. This result could not be verified with the variance analysis and also no association was detected for the 3'UTR SNP.

In humans there are several studies about different SNPs and their influence on behaviour (TACHIKAWA et al. 1999, HATTORI et al. 2001, HÖSING et al. 2004). So in cattle the sequencing 
of the whole gene should follow giving the chance to detect more mutations with possible influence on behaviour.

\section{Acknowledgements}

This work was financially supported by the DFG (SFB299). We thank Holger Mathiak and Carina Urban for conducting the behaviour tests.

\section{References}

Boissy A, Bouissou MF (1988) Effects of early handling on heifer's subsequent reactivity to humans and to unfamiliar situations. Appl Anim Behav Sci 20, 259-73

Burrow HM (1997) Measurement of temperament and their relationship with performance traits of beef cattle. Anim Breed Abstr 478-95

Gauly M, Mathiak H, Erhardt G (2002) Genetic background of behavioural and plasma cortisol response to repeated short-term separation and tethering of beef calves. J Anim Breed Genet 119, 379-84

Hattori E, Yamada K, Toyota T, Yoshitsugu K, Toru M, Shibuya H, Yoshikawa T (2001) Association studies of the $C T$ repeat polymorphism in the $5^{\prime}$ upstream region of the cholecystokinin $B$ receptor gene with panic disorder and schizophrenia in Japanese subjects. Am J Med Genet 105, 779-82

Horinouchi Y, Akiyoshi J, Nagata A, Matsushita H, Tsutsumi T, Isogawa K, Noda T, Nagayama H (2004) Reduced anxious behavior in mice lacking the CCK2 receptor gene. Eur Neuropsychopharmacol 14, 157-61

Hösing VG, Schirmacher A, Kuhlenbaumer G, Freitag C, Sand P, Schlesiger C, Jacob C, Fritze J, Franke P, Rietschel M, Garritsen H, Nothen MM, Fimmers R, Stogbauer F, Deckert J (2004) Cholecystokinin - and cholecystokinin-B-receptor gene polymorphisms in panic disorder. J Neural Transm Suppl 147-56

Le Neindre P, Trillat G, Sapa J, Menissier F, Bonnet JN, Chupin JM (1995) Individual differences in docility in Limousin cattle. J Anim Sci 73, 2249-53

Raud S, Runkorg K, Veraksits A, Reimets A, Nelovkov A, Abramov U, Matsui T, Bourin M, Volke V, Koks S, Vasar $E$ (2003) Targeted mutation of CCK2 receptor gene modifies the behavioural effects of diazepam in female mice. Psychopharmacology (Berl) 168, 417-25

Tachikawa H, Harada S, Kawanishi Y, Okubo T, Shiraishi H (1999) Novel polymorphism in the promoter and coding regions of the human cholecystokinin $B$ receptor gene: an association analysis with schizophrenia. Am J Med Genet 88, 700-4

Tulloh NM (1961) Behaviour Of Cattle In Yards. I. Weighing, order and behaviour before entering scales. Anim Behav 9, 25-30

Wang H, Wong PT, Spiess J, Zhu YZ (2005) Cholecystokinin-2 (CCK2) receptor-mediated anxiety-like behaviors in rats. Neurosci Biobehav Rev 29, 1361-73

Received 17 August 2009, accepted 10 March 2010.

Corresponding author:

GEORG ERHARDT

email: georg.erhardt@agrar.uni-giessen.de

Department of Animal Breeding and Genetics, Justus-Liebig-University of Giessen, Ludwigstr. 21 B, 35390 Giessen, Germany 